مقايسه اطلاعات بارش ماهوارواى PERSIANN و TRMM-3B42 V7 با مشاهدات ايستخاههاى

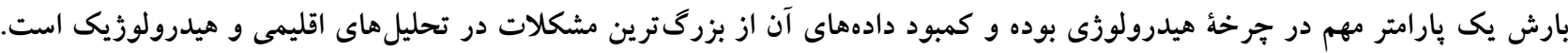

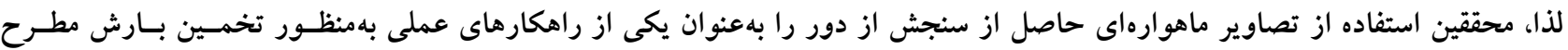

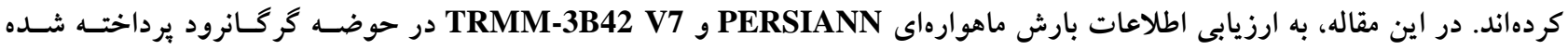

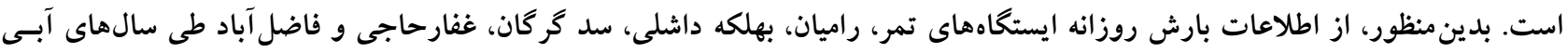

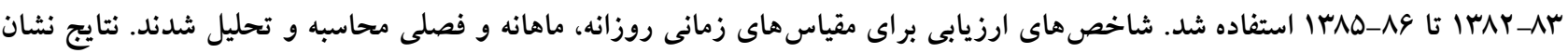

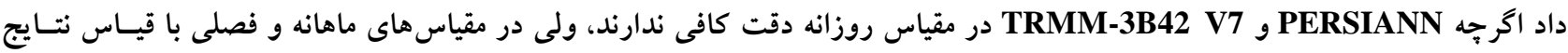

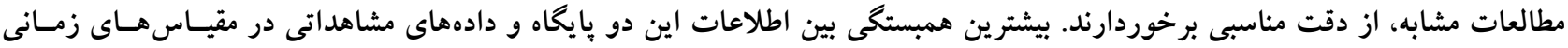

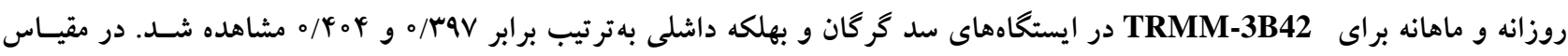

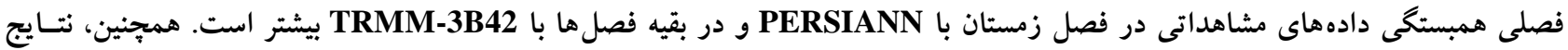

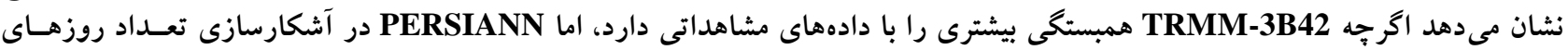
بارانى نتايج بهترى را ارائه كرده است.

وازههاى كليدى: بارش روزانه، تخمين بارندگى، تصاوير ماهوارهاى، سنجش از دور 
Neural Remotely Sensed Information using Artificial Climate Prediction center ) CMORPH g (Network Multi-satellite ) TMPA V7 ‘(Morphing technique

Measuring Mission (TRMM) Precipitation Analysis Asian ) APHRODITE و يايخاههـاى داده Tropical Rainfall Precipitation Highly Resolved Observational Data g (Integration Towards Evaluation of water resoureces (The Global Precipitation Climatology Centre) GPCC اشاره كرد.

الخوريتمهـاى PERSIANN و TMPA V7 داراى قـدرت تفكيـك مكــانى (درجــه ه广/ مك ) و بــهترتيـب داراى قـدرت تفكيك زمانى Dh/o و Th هستند. الخـوريتم CMORPH داراى تفكيك مكانى \&/ / و (Y). با اين وجود، مقادير بارش اين الخوريتمها بهعلت ماهيت اندازه گيرى غيرمستقيم لازم است قبل از استفاده مورد ارزيابى و

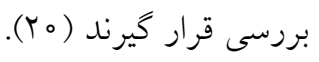

يزّوهشهاى زيادى در سطح جهـان و ايـران در ايسن زمينـه انجام شده است كه در ادامه به برخسى از آنهـا اشـاره مسى شـود.

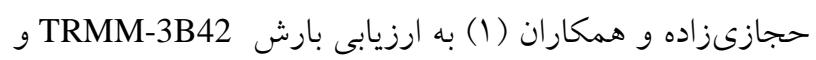

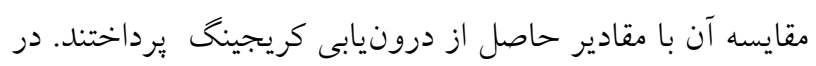
اين مطالعه، مجموع بارش ماهانه و سـالانه حاصـل از-TRMM

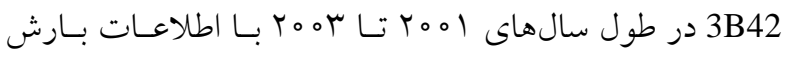
ايستخاه هاى سينويتيك سازمان هواشناسى مقايسه شـدند. نتـايج تحقيق ايشان بيانخر آن بود كه ميزان دقت اين دادههـا در سـطح ايران متفاوت است. بهطورى كه در جنوب رشته كوههاى البرز و نواحى مركزى و تا اندازهاى نواحى شرقى ايـران دقـت مناسـبى ندارند؛ اما در نواحى غربى و جنوبـغربى كشـور دقـت آنهـا را

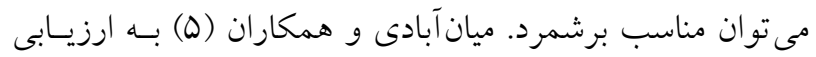
آمارى خروجى الخوريتم CMORPH در بــرآورد بـارش شـمال شرق ايران برداختند. نتـايج تحقيـق ايشـان نشـان داد كـه ايسن

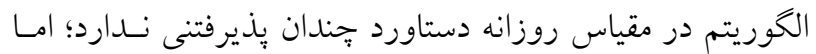
در مقياس ماهانه و فصلى، يافتـههـا از دقـت بـالايى برخـوردار

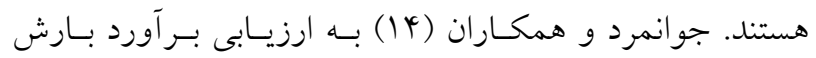
بارش يكى از مهمترين ورودىىهـاى مــلهــاى هيـدورلوزى و گૂاهى است (ه). تغييرات زمانى و مكانى زياد اين متغيـر، آن را به يكى متغير بحثث برانخيز در مدلهاى جـوى- اقليمسى تبـديل كرده است (Y). كمبود دادههـاى قابـل اعتمـاد و كامـل يكسى از مهمترين جالشها در تجزيه و تحليل بـارش و يـيشبينسىهـاى هيدورلوزيك در مديريت منابع آب است (Yo). در كشور ايران، دادههاى بــارش انــازهذيـرى شــده در بسـيارى از نقــاط داراى محدوديت است. براى غلبه بر اين محدوديت، مىتوان از انـواع

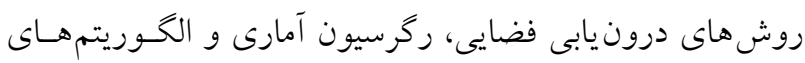
تخمين بارندگى با كمك تصاوير ماهوارهاى استفاده كرد. خطاى روش هاى درون يابى در مناطق مرتفـع و كوهسـتانى، خشـى و نيمسهـشـك بسـيار بالاسـت (r). از اينـرو، در دو دهـهُ اخيـر، مطالعات زيادى جهت توسعه روش هاى مختلـف انـدازهذيـرى بارش با استفاده از تصـاوير مـاهوارهاى بــراى افـزايش دقـت و تخمين بارش در مناطق فاقد آمار كامل و قابـلاعتمـاد صـورت كرفته است (19).

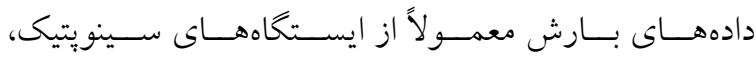
كليماتولوزى و بارانسنجى در بازههاى زمانى مختلف برداشـت مى شود. تعداد ناكافى، تيراكندگى مكانى نامناسب اين ايستخاههـا و عدم يايش در فاصله زمانى كوتاه مدت از مشكلات هميشكى كاربران دادههاى بارش است (Y). همحِيني، روش هاى سنتى نيز بهعلت احتمال اشتباه كاربر، حساسيت و خرابسى دسـتخاه، عـدم امكان استقرار دستخاههاى ثبت كننده در مناطق صعبالعبور گـاه

$$
\text { از دقت خوبى برخوردار نيستند. }
$$

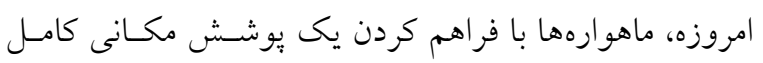
قادر به تخمين بارش براى كل جهان هستند. با انجام ايسن مهـمه، به خصـوص در كشـورهاى درحسالتوسـعه ماننـــ ايـران كـه در بسيارى از حوضههـاى آن آمـار مناسـبى از دادههـاى بارنـدكى موجود نيست، اطلاعات بارش در اختيار قرار گرفته است (Yo). از جمله منـابعى كـه مسى تـوان از بارنـدكى آنهـا اسـتفاده كـرد، الخوريتمهـاى Precipitation Estimation from ) PERSIANN 
با با آستخاه بارانسنجى در شمال مر اكش بهمنظـور (RT V7

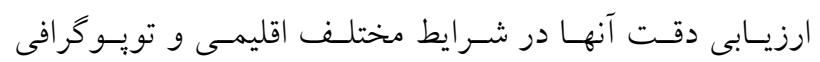

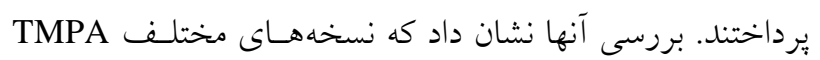

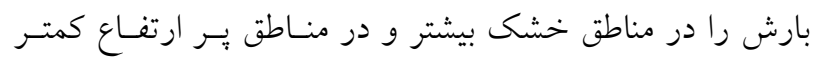

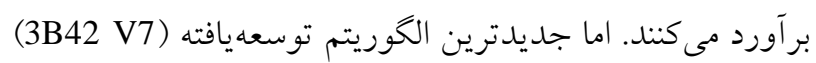

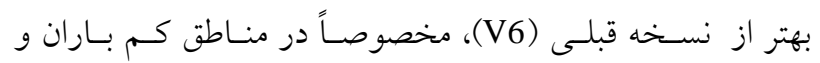

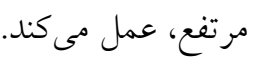

باتوجه به اهميت اطلاعات بارش، تخمين دقيـق آن همـواره

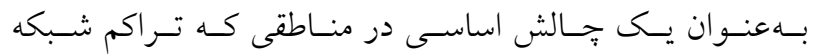

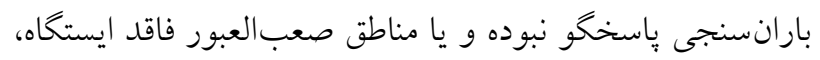

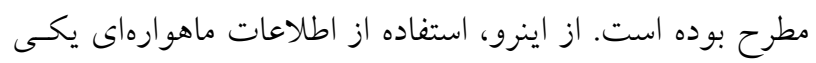
از راهكارهاى ييشرو براى دستيابى به دادههـيـى بـارش در ايسن

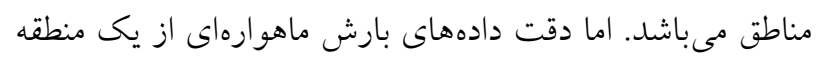

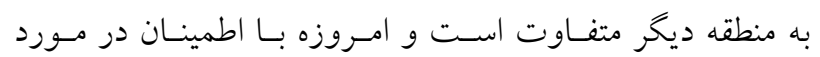

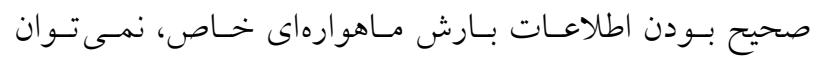

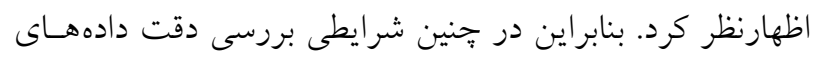

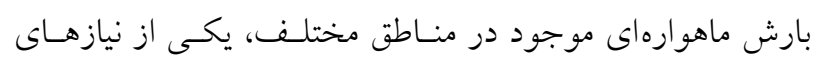

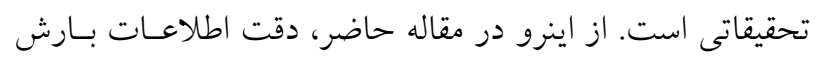

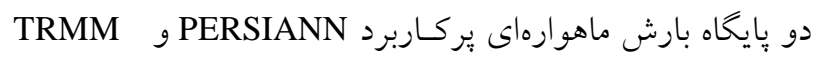

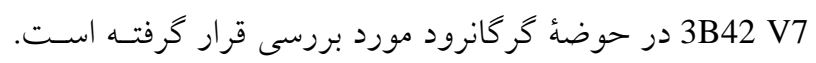

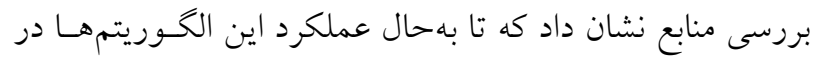

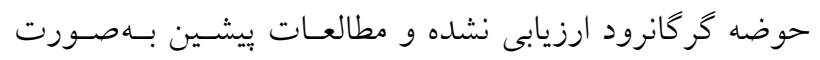
منطقهاى نواحى اطراف درياى خزر را در نظر كرفتهاند.

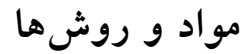

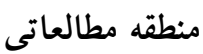

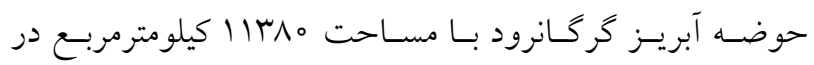
شمال كشور و در جنوب شرقى درياجه خزر واقع شـده اسـت.

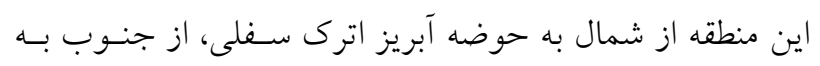

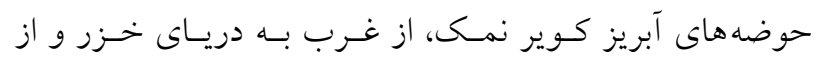
جنوبغ غربى به حوضه نكارود محـدود شــه اسـت. ارتفاعـات البرز بخشهاى جنوبى و شرقى حوضه را تشكيل مسىدهنـد. از
TRMM-3B42 V6

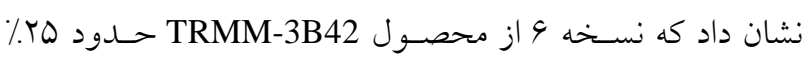

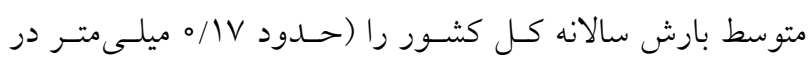
روز) كمتر تخمين مىزند.

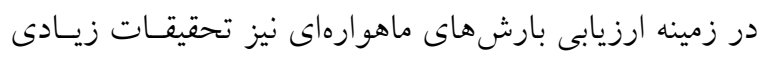

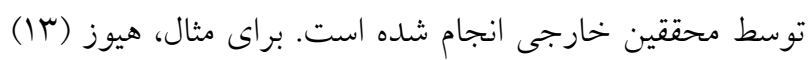

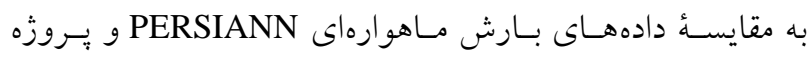

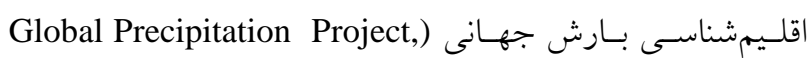

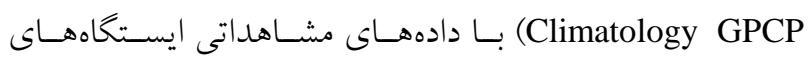

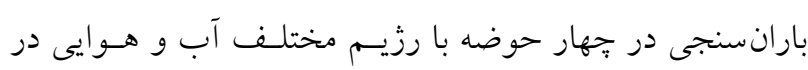

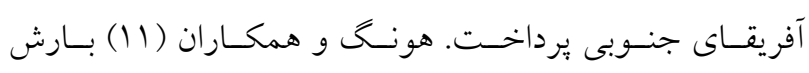

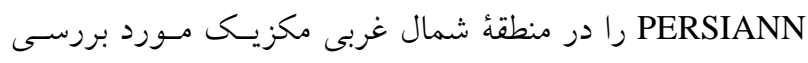

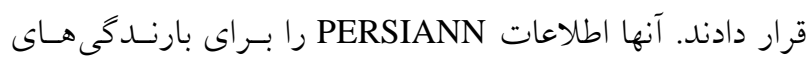

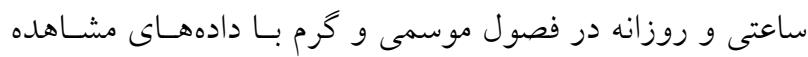

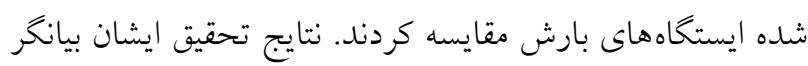

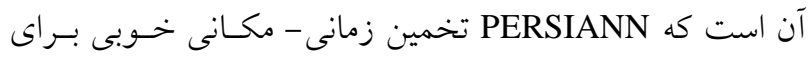
بارندكى در مناطق مورد مطالعه داشته اسـت. كيـزا و همكــاران

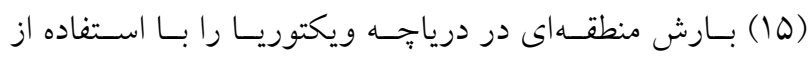

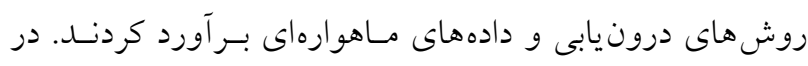

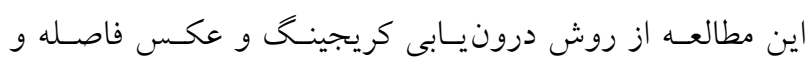

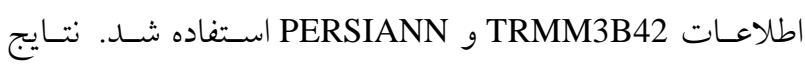
TRMM- (Bias) تحقيق اخير نشان داد كه ميانخين تفاوتهـات

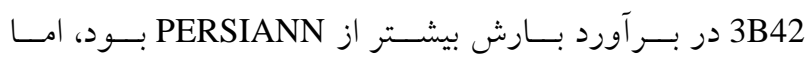

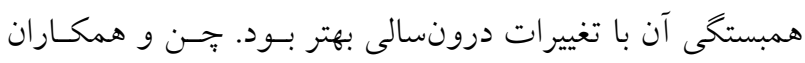

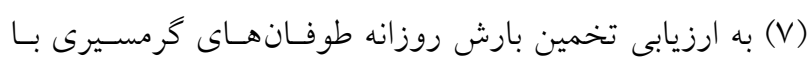

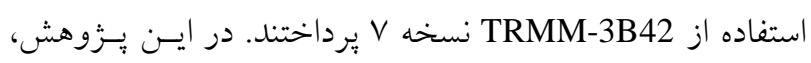

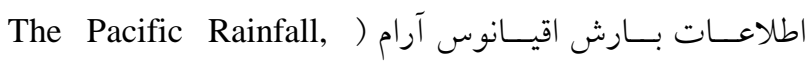
TRMM- به عنوان مرجع براى ارزيسابى اطلاعـات (PACRAIN

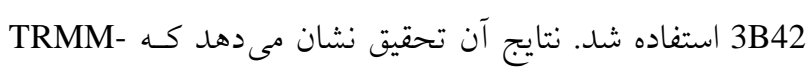

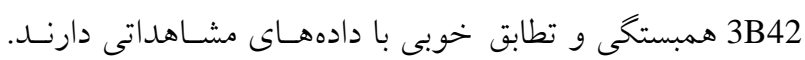

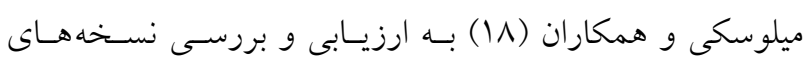

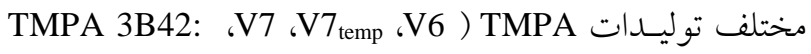


جدول ا. مشخصات ايستخاههاى بارانسنجى منتخب در حوضه گر كانرود

\begin{tabular}{|c|c|c|c|c|}
\hline \multirow{2}{*}{$\begin{array}{l}\text { ميانخين بارندگى } \\
\text { سالانه (ميلى متر) }\end{array}$} & \multirow{2}{*}{ ارتفاع } & \multicolumn{2}{|c|}{ مختصات جغرافيايى } & \multirow[t]{2}{*}{ نام ايستخاه } \\
\hline & & عرض & طول & \\
\hline$\Delta V r$ & ITr & $r v^{\circ} r q^{\prime}$ & $\Delta \Delta^{\circ} \Delta \mathcal{G}^{\prime}$ & تمر \\
\hline$\Lambda \Delta \wedge$ & roo & $m V^{\circ} \circ l^{\prime}$ & $\Delta \Delta^{\circ} \circ \Lambda^{\prime}$ & ر اميان \\
\hline rar & TY & $r v^{\circ} \circ \psi^{\prime}$ & $\Delta Y^{\circ} Y V^{\prime}$ & بهلكه داشلى \\
\hline Trt & Ir & $r V^{\circ} I r^{\prime}$ & $\Delta Y^{\circ} Y \varphi^{\prime}$ & سد گر گان \\
\hline red & $-M t$ & $r V^{\circ} \mid r^{\prime}$ & $\Delta Y^{\circ} Y \Delta^{\prime}$ & فاضل آباد \\
\hline$q V V^{4}$ & Ylo & $r V^{\circ} \circ o^{\prime}$ & $\Delta Y^{\circ} \circ \Lambda^{\prime}$ & غفارحاجى \\
\hline
\end{tabular}

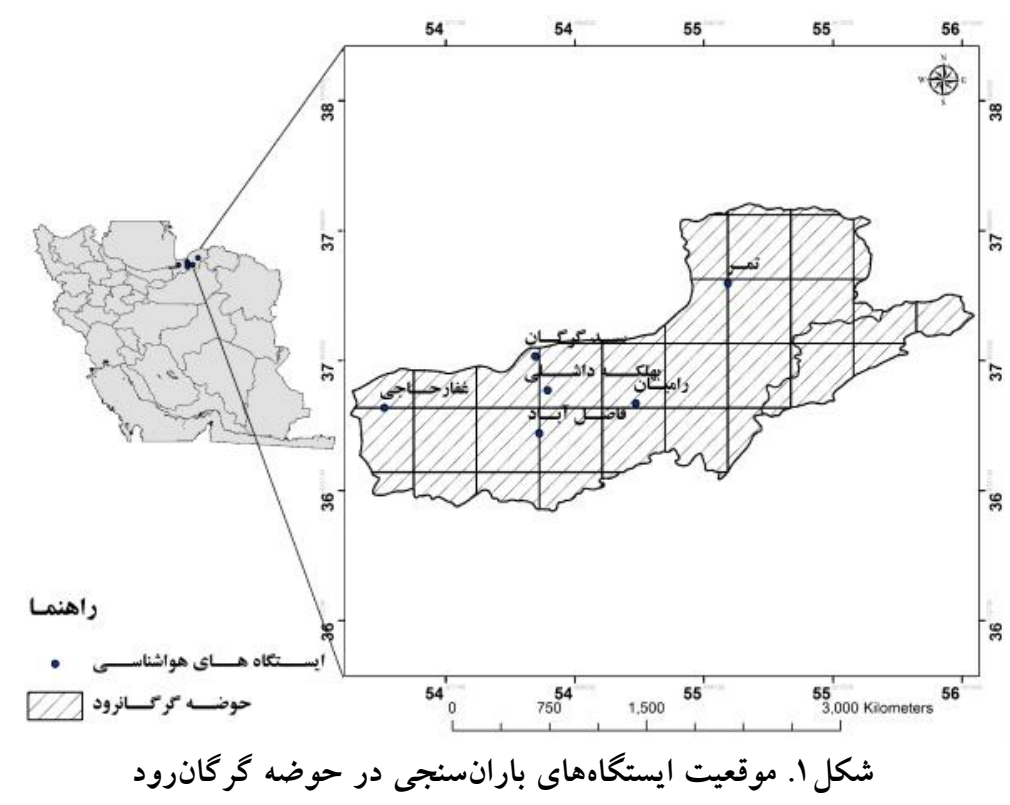

\section{Pحصولات بارش PERSIANN} مدل PERSIANN يك الكوريتم تخمين بارندكى بـا اسـتفاده از سنجش از دور با بهكارگيرى شبكه عصسبى مصسنوعى مسىباشــ (T)( شو و همكاران (r) اين مدل را در سال 1999 در دانشگاه

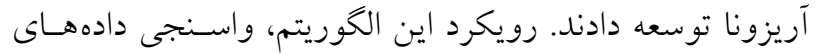
مادونقرمز (Infrared, IR) با برآوردهاى ميكروويوهاى غيرفعال است كه توسط بـهروزرسـانى (Passive Microwaves, PMW) بارامترها در هر زمان كه برآورد PMW در دسترس است، انجام

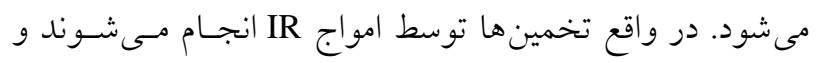

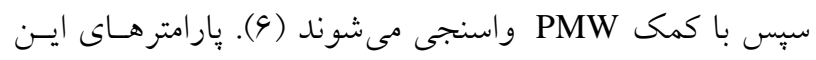

نظر موقعيت جغرافيايى اين حوضه بين عرضهـاى جغر افئائي

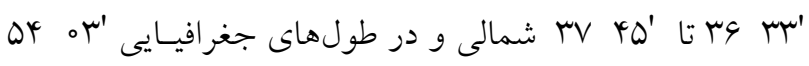
تا 'سا

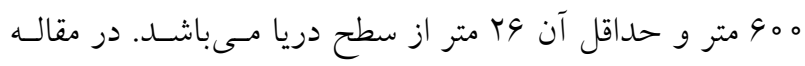

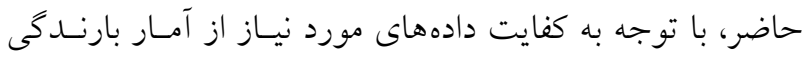
روزانهُ شش ايستّاه تمر، راميـان، بهلكـه داشـلى، ســـ كركـان،

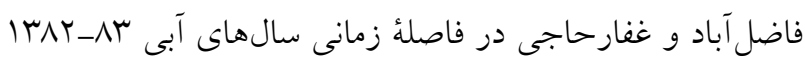

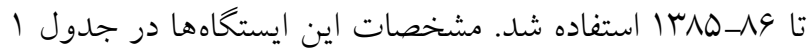
و موقعيت جغرافيايى آنها در شكل ا ارائه شده است. 


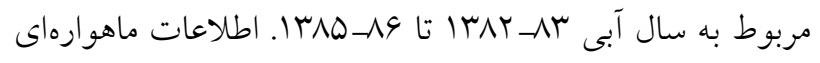

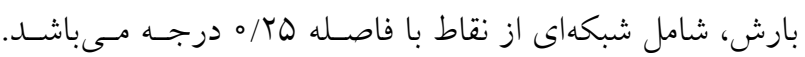

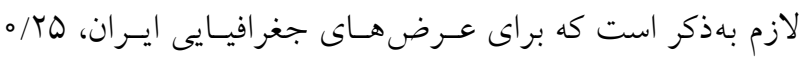

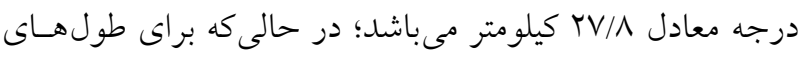

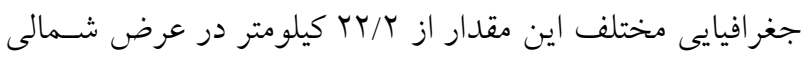

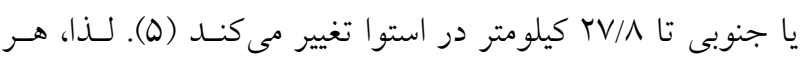

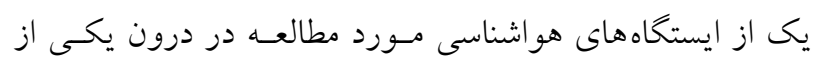

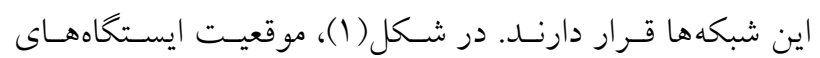
هواشناسى و شبكههاى متناظر نشان داده شده است.

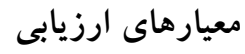

براى ارزيابى دقت اطلاعات بارش مـاهو ارهاى، از جهـار معيـار

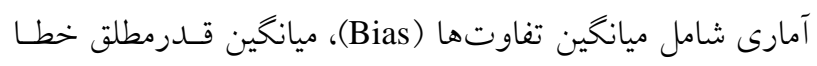

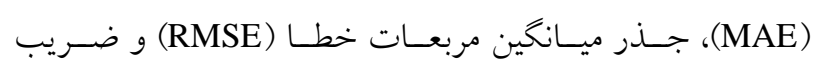

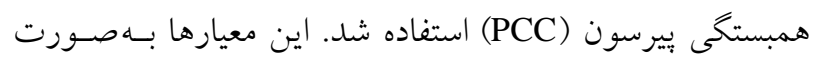
زير تعريف مىشوند (19):

Bias $=\frac{\sum_{\mathrm{i}=1}^{\mathrm{N}}\left(\mathrm{P}_{\mathrm{S}_{\mathrm{i}}}-\mathrm{P}_{\mathrm{O}_{\mathrm{i}}}\right)}{\mathrm{N}}$

$M A E=\frac{\sum_{i=1}^{N}\left|P_{S_{i}}-P_{O_{i}}\right|}{N}$

RMSE $=\sqrt{\frac{\sum_{\mathrm{i}=1}^{\mathrm{N}}\left(\mathrm{P}_{\mathrm{S}_{\mathrm{i}}}-\mathrm{P}_{\mathrm{O}_{\mathrm{i}}}\right)^{r}}{\mathrm{~N}}}$

$\mathrm{PCC}=\frac{\sum_{\mathrm{i}=1}^{\mathrm{N}}\left(\mathrm{P}_{\mathrm{S}_{\mathrm{i}}}-\overline{\mathrm{P}_{\mathrm{S}}}\right)\left(\mathrm{P}_{\mathrm{O}_{\mathrm{i}}}-\overline{\mathrm{P}_{\mathrm{O}}}\right)}{\sqrt{\sum_{\mathrm{i}=1}^{\mathrm{N}}\left(\mathrm{P}_{\mathrm{S}_{\mathrm{i}}}-\overline{\mathrm{P}_{\mathrm{S}}}\right)^{r}} \sqrt{\sum_{\mathrm{i}=1}^{\mathrm{N}}\left(\mathrm{P}_{\mathrm{O}_{\mathrm{i}}}-\overline{\mathrm{P}_{\mathrm{O}}}\right)^{r}}}$

در روابـط بــالا ، مقـدار بــارش مــاهوارهاى در خــام زمـانى

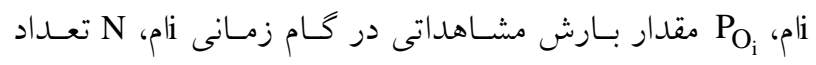
دادههاى بارش،

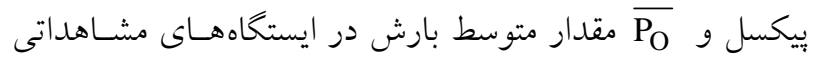

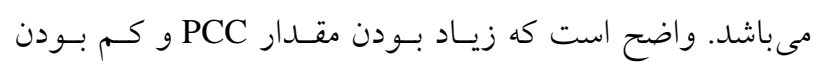

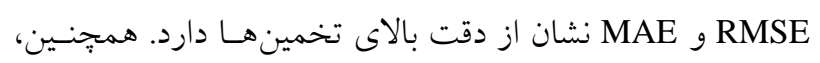

مدل، بهطور منظم با استفاده از تصاوير ماهوارههاى با مدار يايين NOAA-16 NOAA-15 TRMM ــ مانن (Low-orbital)

Defense Meteorological ) DMSP F13 NOAA-17 Fatellite Program و F14 م15 بهروز مىشوند. با اسـتفاده از

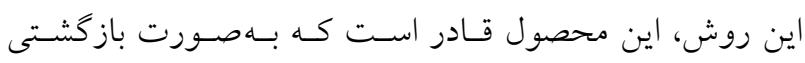

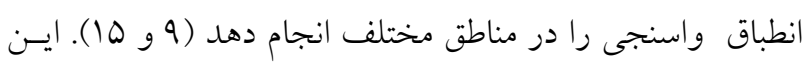

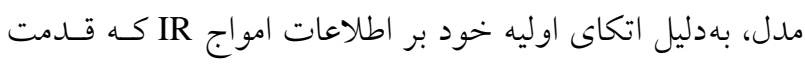

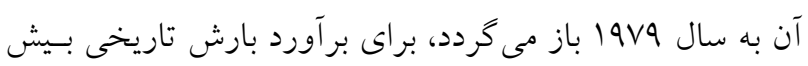
از سه دهه كُشته بسيار مناسب است (9).

محصولات بارش TRMM

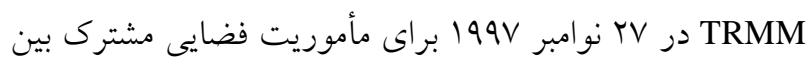

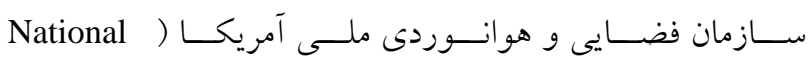
Aeronautics and Space Administration, NASA اكتشافات هوا فضاى زاين (Japanese Aerospace Exploration (Agency, JAXA

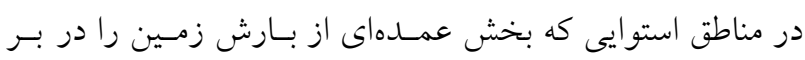

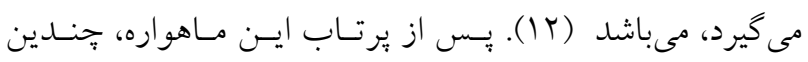
نسخه از دادهاى بارش حاصل از اين ماهواره توليد شده است.

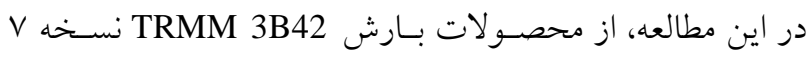

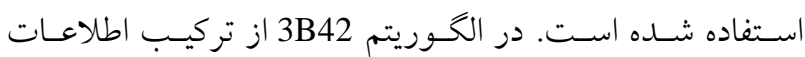

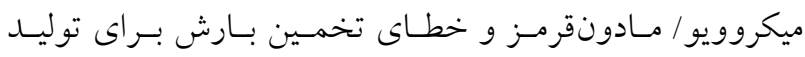

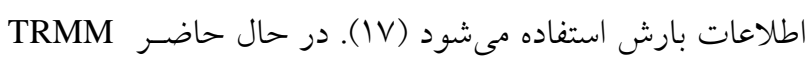

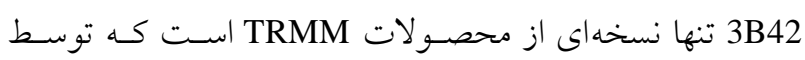

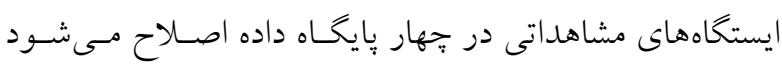

$$
\text { روش كار }
$$

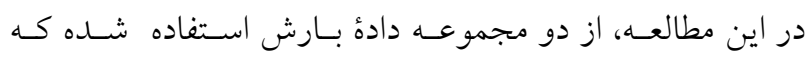

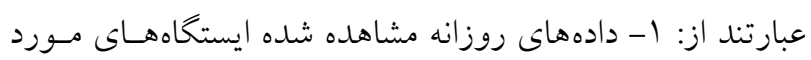

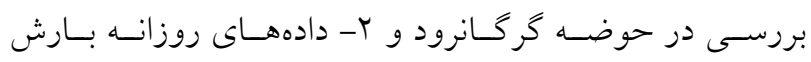

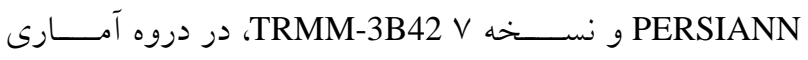


كرفتن اثر تغيير فصـلهـا صـورت كرفـت. در مقيـاس روزانـه،

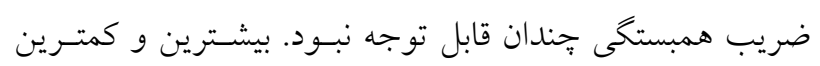
مقدار همبستكى دادههاى PERSIANN با بارش روازنه ايستخاه

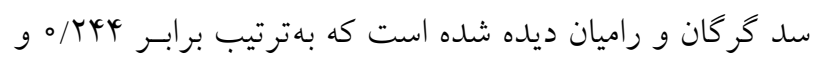

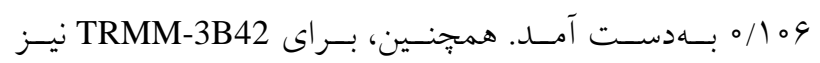
بيشترين و كمتـرين ضـريب همبسـتخى در همسين دو ايستخاه

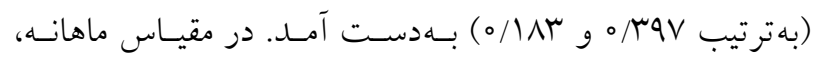

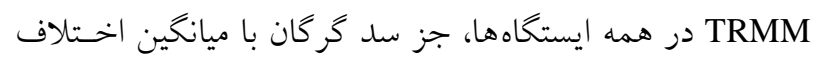

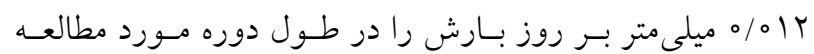

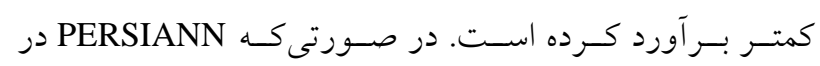

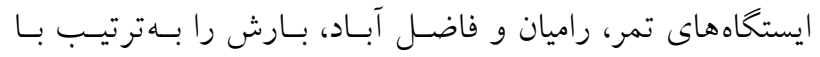

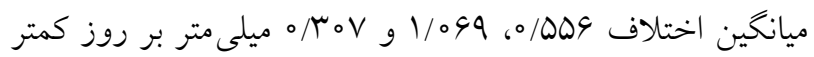

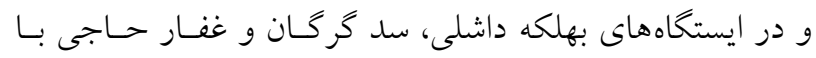

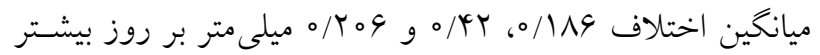

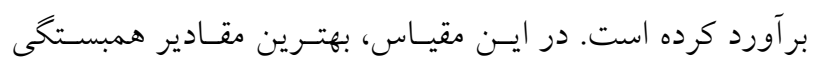
PERSIANN

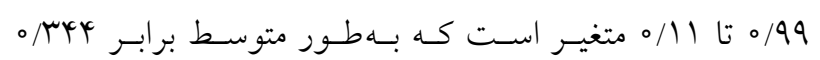
محاسبه شد. در TRMM نيز بهترين مقادير همبستخى ماهانه در

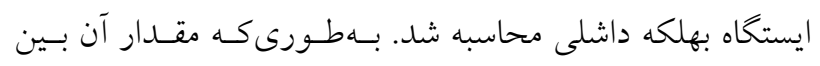

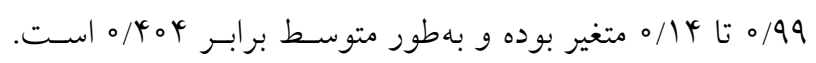

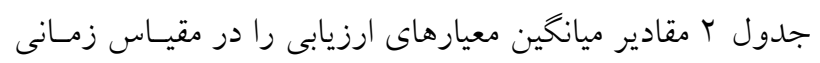

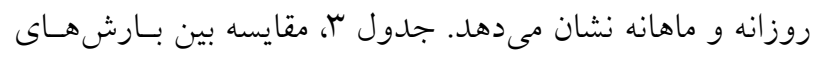

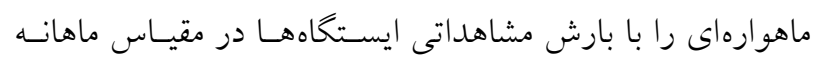

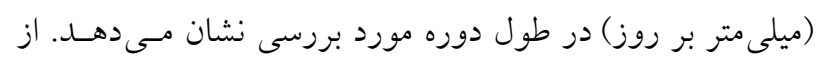

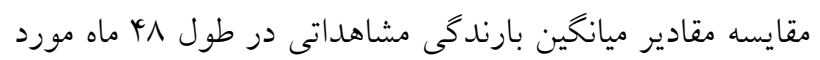

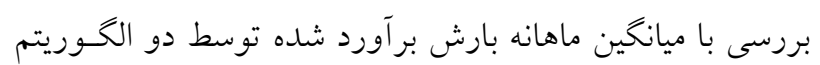

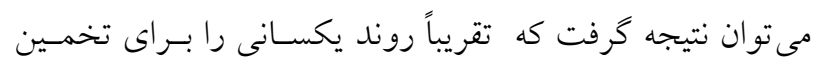

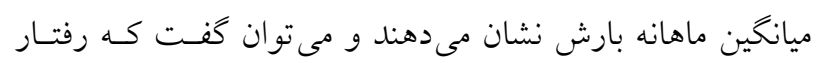

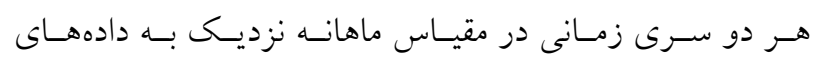

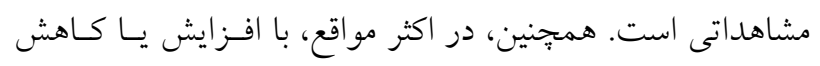
بارش مشاهداتى، بارش ماهوارهاى نيز افزايش يـا كـاهش يافتـه
مقادير منفى و مثبت Bias بـهـترتيـب بـهمعنـاى كـم تخمينسى و بيشتخمينى اطلاعات ماهوارهاى است.

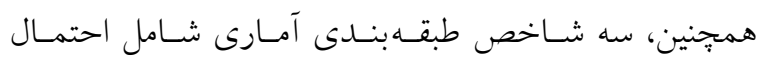

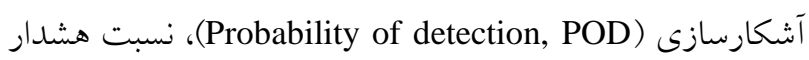

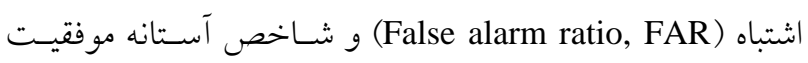

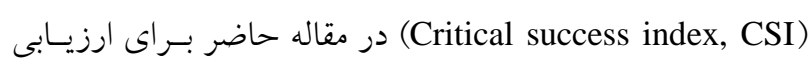

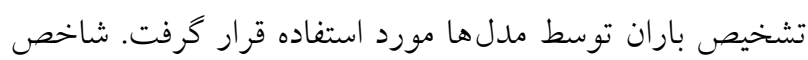

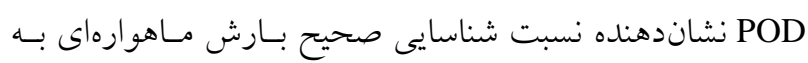
تعلداد كل رخهـدادهـاى بـارش مشــاهده شــده در ايستخاههـاى

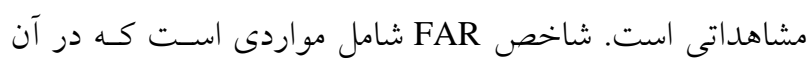

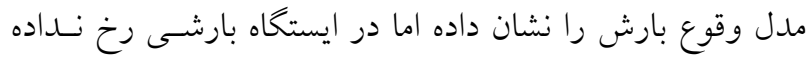

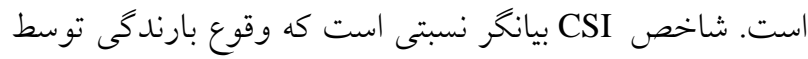
ماهواره به درستى تشخيص داده شده است (19).

$\mathrm{POD}=\frac{\mathrm{a}}{\mathrm{a}+\mathrm{c}}$

$\mathrm{FAR}=\frac{\mathrm{b}}{\mathrm{a}+\mathrm{b}}$

$\mathrm{CSI}=\frac{\mathrm{a}}{\mathrm{a}+\mathrm{b}+\mathrm{c}}$

در معادلات بالا، a تعداد دفعاتى است كـه بـاران مشـاهدهشــــ بهدرستى تشـخيص داده شــه، b تعـداد دفعـاتى اسـت كـه در

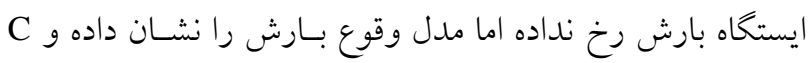
تعداد مشاهداتى است كه باران مشاهدهشده تشخيص داده نشده است. در بهترين حالـت ممكـن، مقـادير POD، CSI ،FAR بـهـ

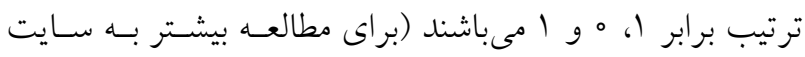
http://www.cawcr.gov.au/projects/verification/\#Methods

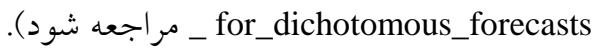

\section{نتايج و بحث}

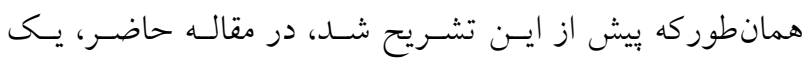

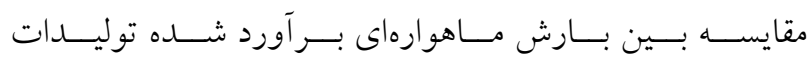

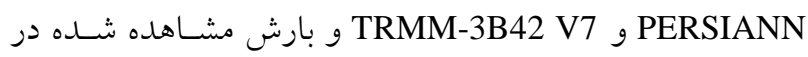

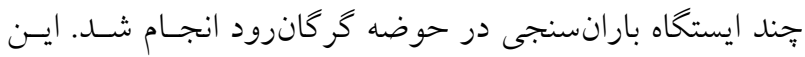

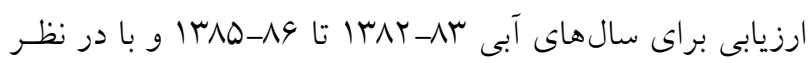


جدولr. ميانگين معيارهاى ارزيابى محاسبه شده در مقياس روزانه و ماهانه در ايستخاههاى مورد بررسى

\begin{tabular}{|c|c|c|c|c|c|c|c|c|c|}
\hline \multicolumn{2}{|c|}{ MAE } & \multicolumn{2}{|c|}{ BIAS } & \multicolumn{2}{|c|}{ RMSE } & \multicolumn{2}{|c|}{$\mathrm{PCC}$} & & \multirow{2}{*}{ شقاخص } \\
\hline ماهانه & روزانه & ماهانه & روزانه & ماهانه & روزانه & ماهانه & روزانه & & \\
\hline$r / 4 Y Y$ & r/MKT & $-\circ / 0 \Delta 9$ & $-\circ / \Delta \Delta r$ & $\Delta / T \Delta Q$ & $0 / \Lambda F$ & $0 /$ TqR & $0 / Y 1 \Lambda$ & PERSIANN & تمر \\
\hline$r / Y \Delta \Lambda$ & $\varphi / \backslash \wedge \varphi$ & $-o /$ MYy & $-0 / \mu y$ & Q/VIT & $G / 4 \wedge V$ & $\circ / \mu \vee V$ & $\circ / Y \wedge V$ & TRMM & \\
\hline$r / r \circ 1$ & $r / \backslash \Lambda \mu$ & $-1 / 099$ & $-1 / 094$ & $V / 911$ & N/VTr & OKYI & $0 / 109$ & PERSIANN & ر راميان \\
\hline T/AYT & $r / \Lambda \circ Y^{r}$ & $-1 / T 9 \Lambda$ & $-1 / 49$ & V/MTV & $1 / 949$ & س את/ם & ०/イץ & TRMM & \\
\hline Y/OFY & $r / \circ Y q$ & ०/1^9 & $\circ / \Lambda \uparrow$ & $\varphi / \mu \Delta \mid$ & c/aAr & $\circ / T V T$ & $0 / 199$ & PERSIANN & بهلكه داشلى \\
\hline 1/OAK & l/DQr & -0/YMY & -OTMY & $r / 919$ & r/grt & $\circ / 4 \circ \varphi^{4}$ & VIrV & TRMM & \\
\hline 1/NMT & INTY & O/YY & $0 / 4 I V$ & $r / v 01$ & $Y / \varphi V T$ & o/Mkt & OMYY & PERSIANN & سد گر گان \\
\hline | & I/TYY & $0 / 01 Y$ & .010 & سוץ/r & $r / 941$ & $\circ / \mu \Lambda \varphi$ & $\circ /$ rqV & TRMM & \\
\hline$r / 490$ & $r / 4 N I$ & $-\circ / \mu \circ V$ & $-0 / \mu \circ \Lambda$ & Q/90r & $9 / 494$ & سוr/ & $0 / 199$ & PERSIANN & فاضل آباد \\
\hline Y/OGY & $r / \circ \Delta Y$ & $-\circ / \wedge \Delta \wedge$ & - ०/AQT & $0 / \circ 99$ & $0 / 9 \mu_{\Lambda}$ & $\circ / \mu \Delta V$ & $\circ / \mu \circ q$ & TRMM & \\
\hline T/YGY & Y/YYV & $\circ / Y \circ 4$ & $\circ / Y \circ Y$ & 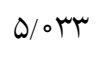 & $G / Y M I$ & o/rqr & $\circ / 191$ & PERSIANN & غفارحاجى \\
\hline I/AYI & $1 / \wedge 1$ & $-0 / T I V$ & $-o / T I Y$ & $r / 90 \mathrm{~V}$ & $0 / 909$ & OMGT & O/MYA & TRMM & \\
\hline
\end{tabular}

تمر، راميان و فاضل آبـاد تمايسل بـه كـمـتخمينسى دارد. در ايسن مقياس هر دو الكوريتم در ايستخاههـاى ســ كرخـان و بهلكـه داشلى تخمين قابـل قبـولى را از بـارش سـاليانه ارائسه كردنــد.

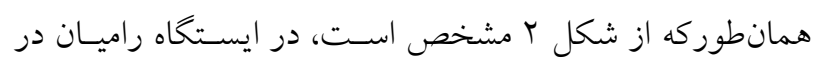
طول دوره مورد مطالعه تخمين مناسبى در مقياس سالانه انجـام نشده است. همـانطـور كـه قـبلاً تشــريح شــ، بــراى مشـخص كـردن محسـدوديت تشـخيص بــارش از طريست الخــوريتمهــاى بـارش ماهوارهاى سه شاخص FAD و FAR ،SI مورد بررسى قـرار كرفت. بيشترين مقادير CSI و POD مربـوط بـه PERSIANN

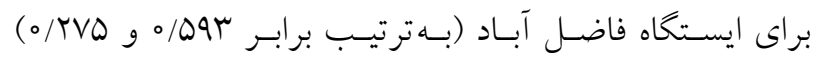

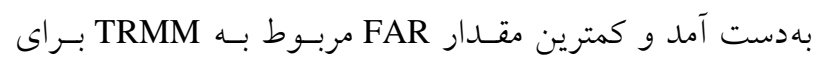
ايستخاه سد گر كان مىباشد. مقادير بالاى POD نشـاندهنــده آن است كه مدل بهخوبى توانسته اسـت تعـداد روزهــاى بـارانى را

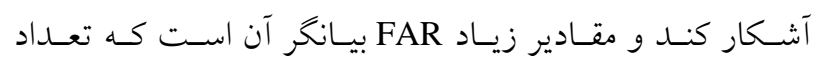

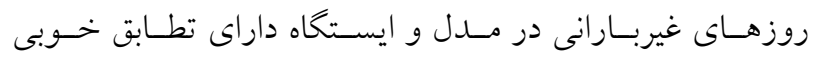
نمىباشند. CSI حدود ب/ه نيز نشان مىدهد كه هر دو توليـدات
براى ايستخاههاى تمر، راميـان و بهلكـهـ داشـلى، بيشـترين همبستخى دادههاى مشاهداتى در فصـل هـاى تابسـتان، بهـار و

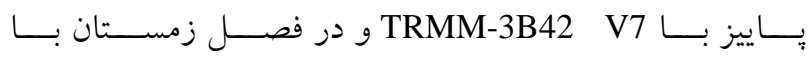
PERSIANN به ثبت رسيد. براى ايسـتخاههـاى فاضـل آبـاد و

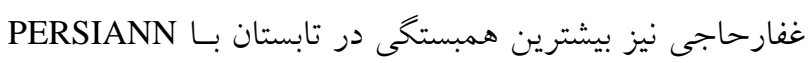
و در بهار، زمستان و باييز با TRMM-3B42 مشـاهده شــد. در ايستخاه سـد گرگـان، PERSIANN در فصـل هــاى تابسـتان و زمستان و TRMM-3B42 در بهار و يُاييز بيشـترين همبسـتخى را با دادههاى مشاهداتى داشتند. بهطوركلى، مىتوان كفـت كـه

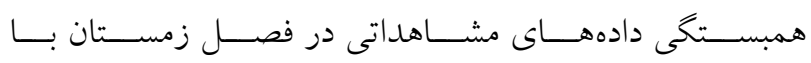
PERSIANN و در بقيـه فصـلهـــا بـا TRMM-3B42 بيشـتر اسـت. كمتــرين مقــادير همبسـتخى در هـر دو سـرى بــارش

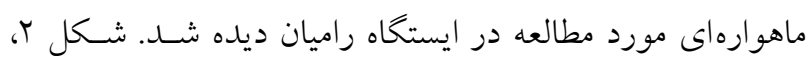
ميـانخين بـارش سـالانه PERSIANN و TRMM را بـا بـارش مشاهداتى ساليانه در طول دوره مورد مطالعه نشان مىدهـــ. در اين مقياس، TRMM به جز ايستخاه سد گر كان بـارش را كمتـر از مقدار واقعى برآورد مى كنـد. PERSIANN در ايسـتخاههـاى 
جدول r. مقايسه بارش ماهانه PERSIANN و TRMM-3B42 با بارش مشاهداتى در ايستخاههاى مورد مطالعه (ميلىمتر بر روز)

\begin{tabular}{|c|c|c|c|c|c|c|c|c|c|}
\hline & آذر & & & 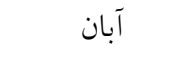 & & & مهر & & \\
\hline TRMM & PERSIANN & مشاهداتى & TRMM & PERSIANN & مشاهداتى & TRMM & PERSIANN & مشاهداتى & ايستخاه \\
\hline $1 / v 4 q$ & $1 / 190$ & $Y / \circ 99$ & $r / Q \circ V$ & INVT & $T / N Q$ & $1 /$ TrA & o/DFA & I/TAT & تم \\
\hline $1 / V \circ D$ & I/KTY & $1 / N D_{0}$ & $r / 04 Y$ & $1 / 900$ & $r /|V|$ & OIGYY & o/vAY & 1/09 & ر اميان \\
\hline $1 / 4 \Delta \Delta$ & $1 / 0 \wedge 9$ & $1 / N Q \circ$ & T/OF & $r / 119$ & $r / \mid V I$ &.$/ 090$ & $0 / 1 / 4$ & $1 / 09 \mu$ & بهلكه داشلى \\
\hline I/OHY & $1 / V \circ r$ & $1 / 4 T D$ & $1 / 900$ & $1 / 901$ & $1 / 991$ & $\circ / D Y V$ & $\circ / 90 \mu$ & DIMTH & سد گر گان \\
\hline $1 / \pi \Delta Y$ & 1/9ro & Y/OKY & I/AVG & Y/TO & T/AM & $\circ / \Delta V r$ & $\circ / \mathrm{V} \wedge 。$ & سMM/ & فاضل آباد \\
\hline \multirow[t]{2}{*}{ I/VVr } & $1 / 0 \circ \Delta$ & $r / l \circ r$ & $r / 199$ & $r / \backslash \wedge r$ & r/AM & $1 / \circ \Delta 9$ & 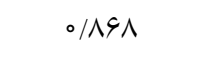 & $\circ / V \circ \Delta$ & 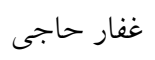 \\
\hline & اسفند & & & بهمن & & & دى & & \\
\hline TRMM & PERSIANN & مشاهداتى & TRMM & PERSIANN & مشاهداتى & TRMM & PERSIANN & مشاهداتى & ايستخاه \\
\hline $1 / \mathrm{V} \mid \circ$ & $r / \circ \Delta T$ & $r / O \wedge Q$ & Y/०VA & $Y / \circ \Delta Y$ & $r / T \Delta \Lambda$ & O/ATY & $1 / 1 \Delta Y$ & T/TTO & تمر \\
\hline $1 / 494$ & r/IVG & $1 / 9 Y \mid$ & I/OrA & T/TA。 & $1 / 9 V 0$ & $1 / 040$ & $1 / 0 \circ 0$ & $1 / 901$ & راميان \\
\hline I/TYY & r/YVI & $1 / 9 Y \mid$ & $1 / \pi V V$ & $r / \mu \circ \varphi$ & $1 / 9 \vee 0$ & $1 / 1 \wedge \circ$ & $1 / 999$ & $1 / 901$ & بهلكه داشلى \\
\hline$\circ / V Q 1$ & $r / r \Delta Q$ & $|/ 4| V$ & $1 / 41 \wedge$ & T/YMT & $1 / 490$ & I/IrA & $1 / 490$ & 1/R. & سد گر كان \\
\hline $1 / 001$ & $r / 999$ & $r / D \circ Y$ & $1 / r \Delta \Lambda$ & $r / \mathcal{Y \mu} \circ$ & $r / \mid \Delta \wedge$ & $1 / T T Q$ & $1 / 7 \wedge 9$ & T/VIV & فاضل آباد \\
\hline \multirow[t]{2}{*}{$1 / 040$} & $r / 9 Y_{0}$ & $1 / \Delta \vee \wedge$ & $1 / \mu \wedge \uparrow$ & $r / \Lambda \circ Y$ & $1 / 0 \Delta 9$ & $1 / 909$ & $1 / N \mu_{0}$ & $r / T \circ D$ & غفار حاجى \\
\hline & خرداد & & & ارديبهشت & & & فروردين & & \\
\hline TRMM & PERSIANN & مشاهداتى & TRMM & PERSIANN & مشاهداتى & TRMM & PERSIANN & مشاهداتى & ايستخاه \\
\hline o/Nkt &.$/ 919$ & $\circ / V \Delta r$ & T/IVT & r/o०r & س & T/MT & T/THA & $T / \Lambda \Delta \Delta$ & تمر \\
\hline $0 / 4 \mid Y$ & $\circ / 9 M V$ & $\circ / \Delta 90$ & $1 / \pi \Delta \Delta$ & T/9MY & $1 / 11 \pi$ & 1/Mry & T/MTV & I/AMI & ر \\
\hline $0 /$ pyq & -NQPr &.$/ 090$ & $1 / 10 \wedge$ & $r / 914$ & $1 / 114$ & $1 / 490$ & r/Y L & I/AYI & بهلكه داشلى \\
\hline$\circ / \mathcal{H} \circ V$ & $0 / 9 \mu q$ & $\circ / \backslash Q V$ & - $9 \Delta r$ & T/TaY & $\circ / \mathrm{D} \Delta \wedge$ & I/VQA & T/OTG & $1 / 9 V \mid$ & سد گر گان \\
\hline$\circ / 0 r q$ & $1 / 101$ & $\circ / 9 \circ r$ & $1 / 414$ & r/VGQ & T/TAY & I/OTA & $r / \Delta Y_{0}$ & $T / 9 \circ V$ & فاضل آباد \\
\hline \multirow[t]{2}{*}{$0 / 499$} & $\circ / 9 \circ 0$ & (سח/: & o/Nkt & $r / 011$ & $0 / 911$ & $1 / 1 / 99$ & $r / \Lambda \circ Y$ & l/AT。 & غفارحاجى \\
\hline & شهريور & & & مرداد & & & تير & & \\
\hline TRMM & PERSIANN & مشاهداتى & TRMM & PERSIANN & مشاهداتى & TRMM & PERSIANN & مشاهداتى & ايستخاه \\
\hline I/KT。 & $\circ / Y \backslash \wedge$ & $1 / 090$ & $\circ / 4 \Delta \wedge$ & $0 / 049$ & ०NGG & $\circ / \mathrm{V} \backslash \Lambda$ & $\circ / 10 \wedge$ & $1 / r 94$ & تمر \\
\hline $0 / Y V T$ & ०/०सG & $0 / 991$ & $\circ / T \circ \Delta$ & $\circ / \circ \wedge \Lambda$ & O & $\circ / \pi \wedge \Delta$ &.$/ 11 \mathrm{~V}$ & $\circ / 0 \circ 4$ & راميان \\
\hline$\circ / 490$ & $0 / 041$ & $0 / 991$ & OMYT & o/l1r & ०/TH人 & $0 / \pi 19$ & $0 / 114$ & $\circ / 0 \circ Y^{r}$ & بهلكه داشلى \\
\hline O/KTV & $0 / 090$ & $0 / 099$ & ०/IV^ & $0 / 010$ & $0 / 104$ & $\circ / \mu \wedge 1$ & olla & $\circ / 4 \circ r$ & سد كر كان \\
\hline$\circ / T V q$ & OOYY &.$/ 911$ & $0 / 191$ & ०.०दा & $\circ / \mu \circ r$ & OMYT & $0 / 19 Y$ & $0 / 119$ & فاضل آباد \\
\hline $0 / 4 \mid r$ & $\circ / \circ V_{0}$ &.$/ 949$ & $\circ / \circ V^{k}$ & $0 / 014$ & .040 & $\circ / \mu q \circ$ & $0 / T 10$ & $\circ / 9 \circ Y$ & غفارحاجى \\
\hline
\end{tabular}




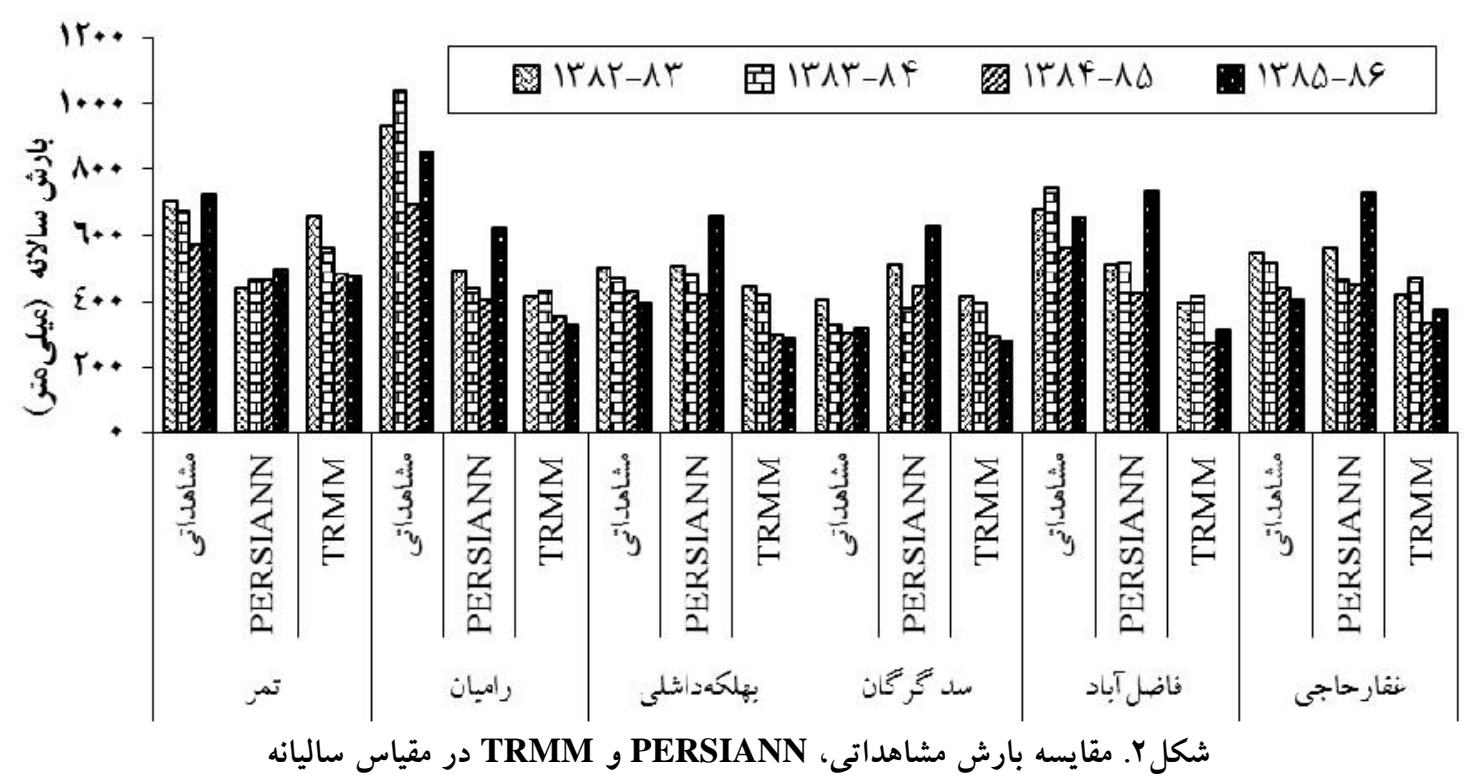

جدول F. مقادير سه شاخص FAR و FOD و CSI در ايستخاههاى مورد مطالعه براى دو ماهواره مطالعه شده

\begin{tabular}{|c|c|c|c|c|c|c|c|}
\hline شاخص & ايستخاه & تمر & راميان & بهلكه داشلى & سد كر كان & فاضل آباد & غفارحاجى \\
\hline \multirow[t]{2}{*}{ POD } & $\begin{array}{c}\text { PERSIAN } \\
\mathrm{N}\end{array}$ & - DDQ & - DMT & $\circ / \Delta \vee \wedge$ & - DQST & $\circ / 094$ & .099 \\
\hline & TRMM & $0 / 799$ & $0 / Y Y q$ & $0 / T V I$ & $0 / Y 90$ & O/TVG & $\circ / T \Delta \wedge$ \\
\hline \multirow[t]{2}{*}{ FAR } & $\begin{array}{c}\text { PERSIAN } \\
\mathrm{N}\end{array}$ & $0 / 9 \vee 9$ & -1909 &.$/ 9 \Lambda \Lambda$ & $\circ / \vee \circ \wedge$ & $0 / 94 Y$ & ONGY \\
\hline & TRMM & $0 / 9 V T$ & $\circ / 09 V$ & -/094 & .099 & $0 / 911$ & $0 / 9 M \Lambda$ \\
\hline \multirow[t]{2}{*}{ CSI } & $\begin{array}{c}\text { PERSIAN } \\
\mathrm{N}\end{array}$ & $\circ / Y \Delta \wedge$ & $0 /$ TSY & - TQA & ०/YM & $\circ / T V D$ & $\circ / Y \circ Y$ \\
\hline & TRMM & $\circ / \backslash \wedge \uparrow$ & ०/AN & $0 / 194$ & $0 / 194$ & $0 / 191$ & $0 / 194$ \\
\hline
\end{tabular}

PERSIANN

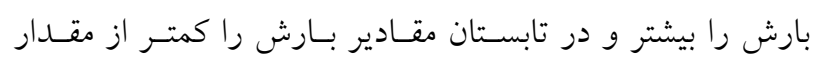

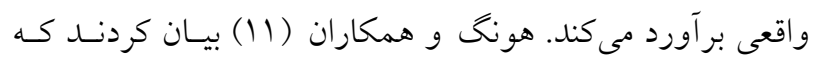

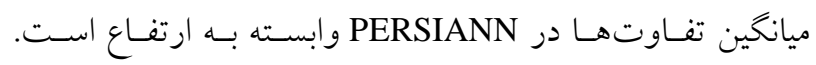

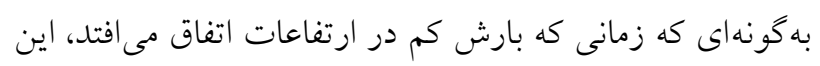

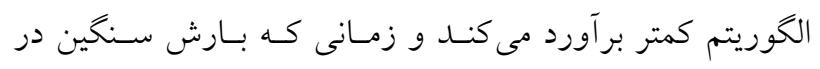

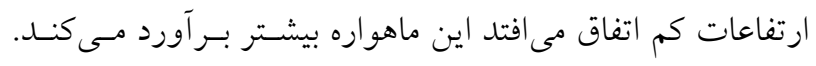

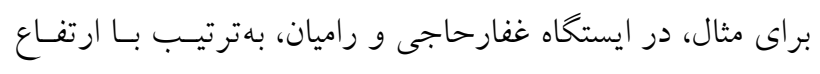

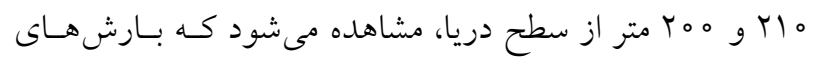

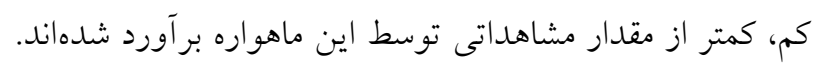

در ايستخاههاى مورد بررسـى بـه خــوبى نتوانسـتهانـــ روزهـاى

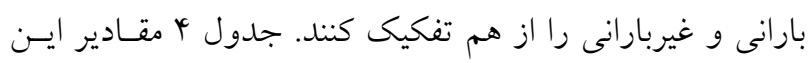

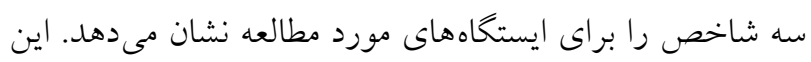

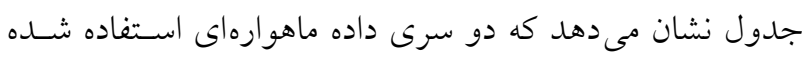

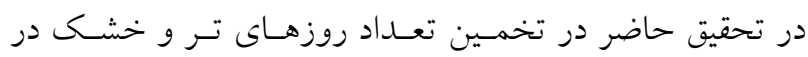

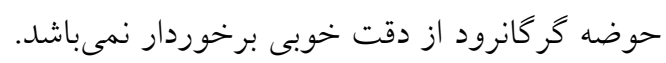

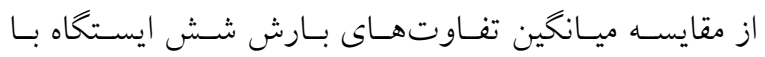

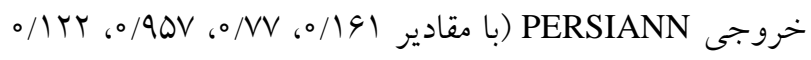

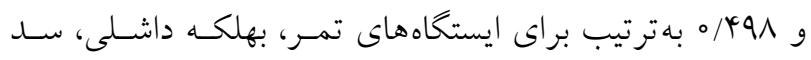

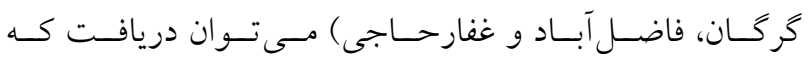




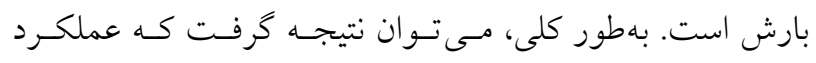

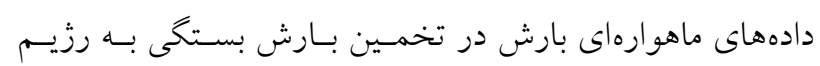

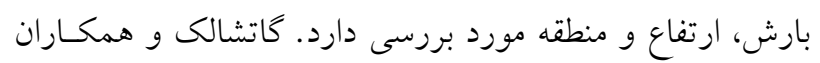

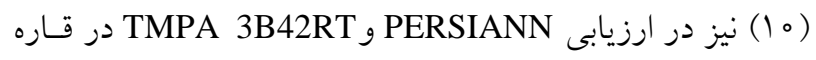

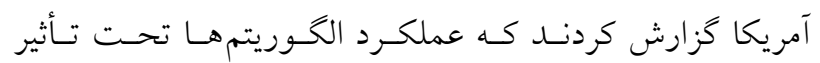
الخوهاى بارش فصلى است.

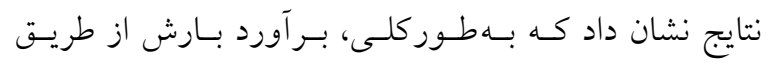

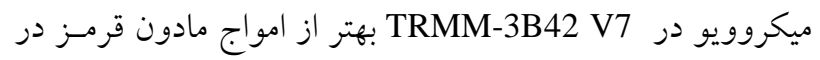
PERSIANN

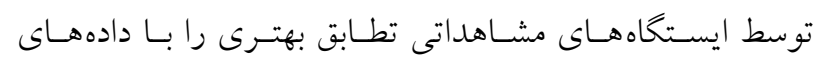

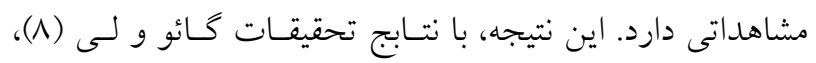

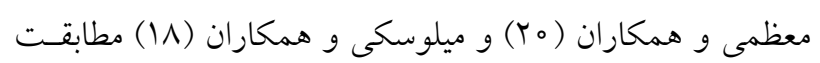

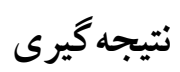

برآورد قابل اعتماد و كمى بارش يكى از ضرورىترين نيازها در

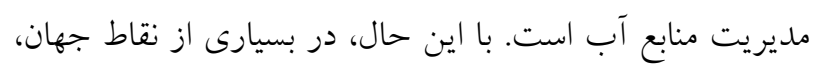

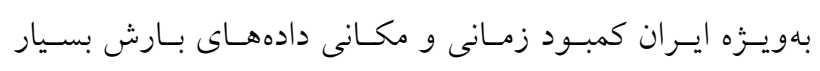

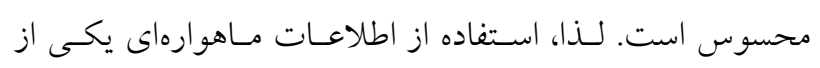

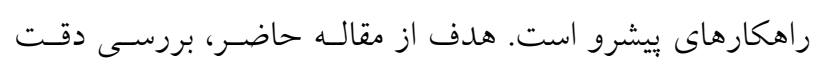

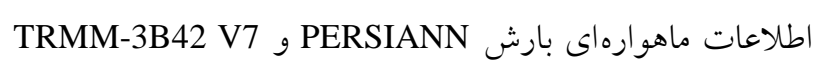

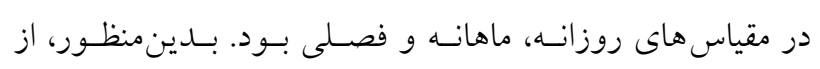

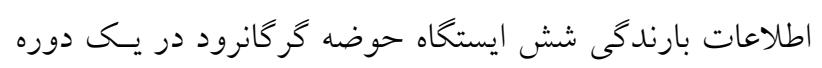

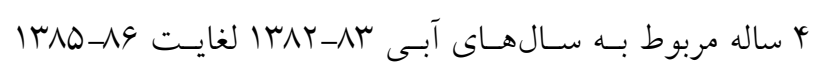

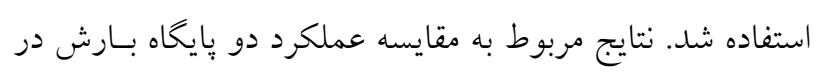

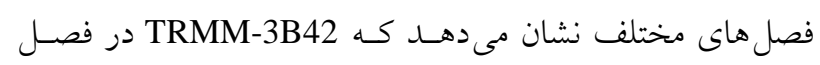

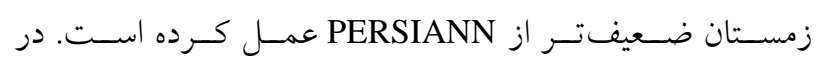

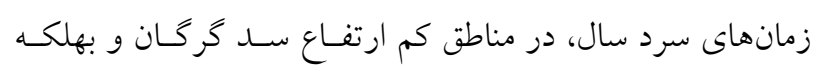

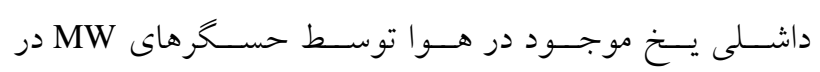

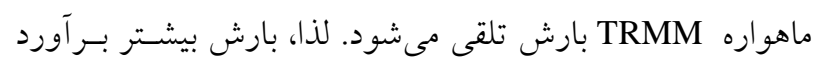

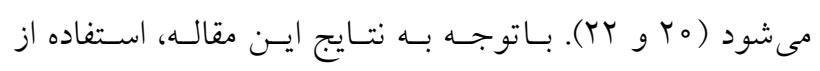

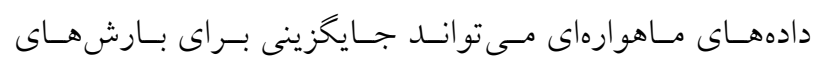

ميـانخَين تفـاوتهــا بــراى TRMM در منـاطق بـا ارتفــاع زيـاد به گونهاى است كه بارش را كمتر برآورد مى كند. براى مثـال، در

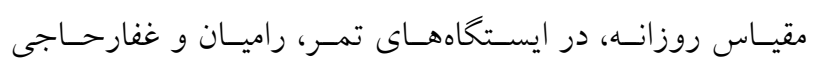

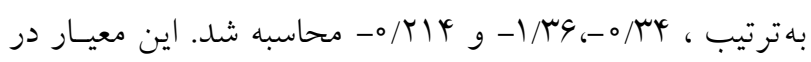

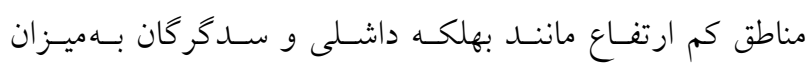

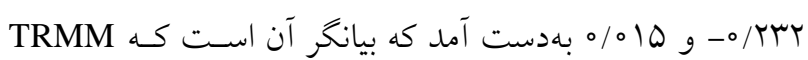
براى اين مناطق تخمين قابل قبولى را ارائه داده است.

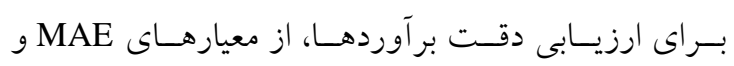
RMSE

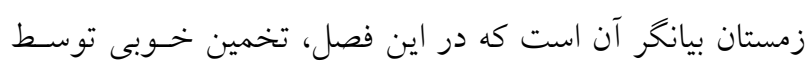

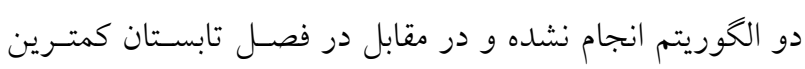

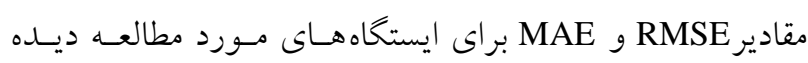
مىشود. در هر دو سـرى توليـدات بـارش مـاهو ارهاى، بهتـرين

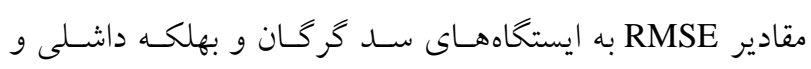

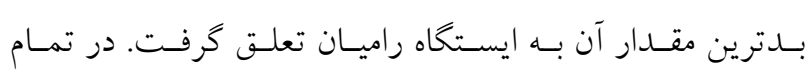

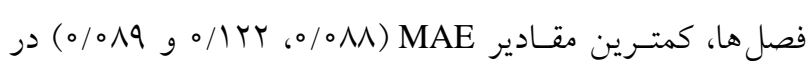

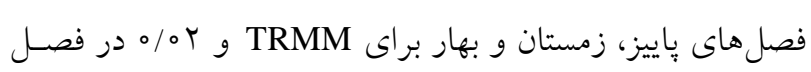

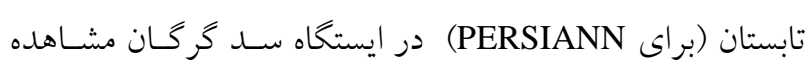

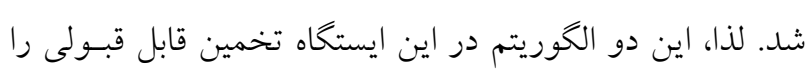

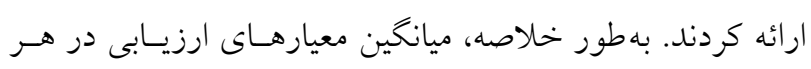

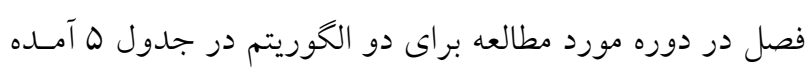

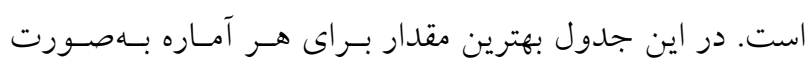
برجسته مشخص شدهاند. از مقايسه اختلاف بين نتـايج مــل ول و بـارش در طـول دوره

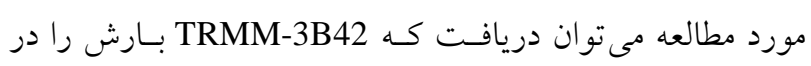

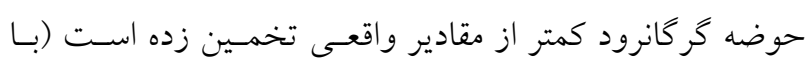

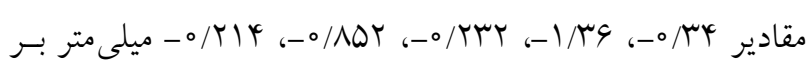

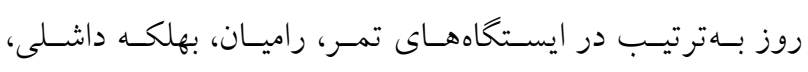

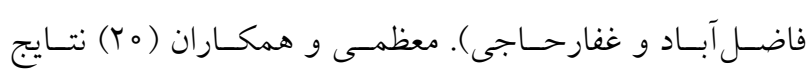

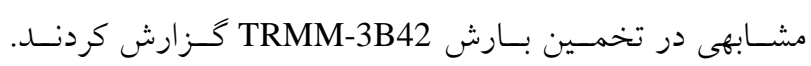

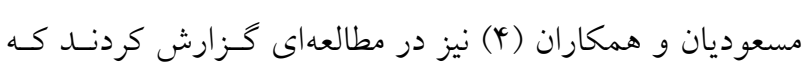

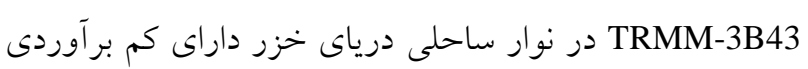




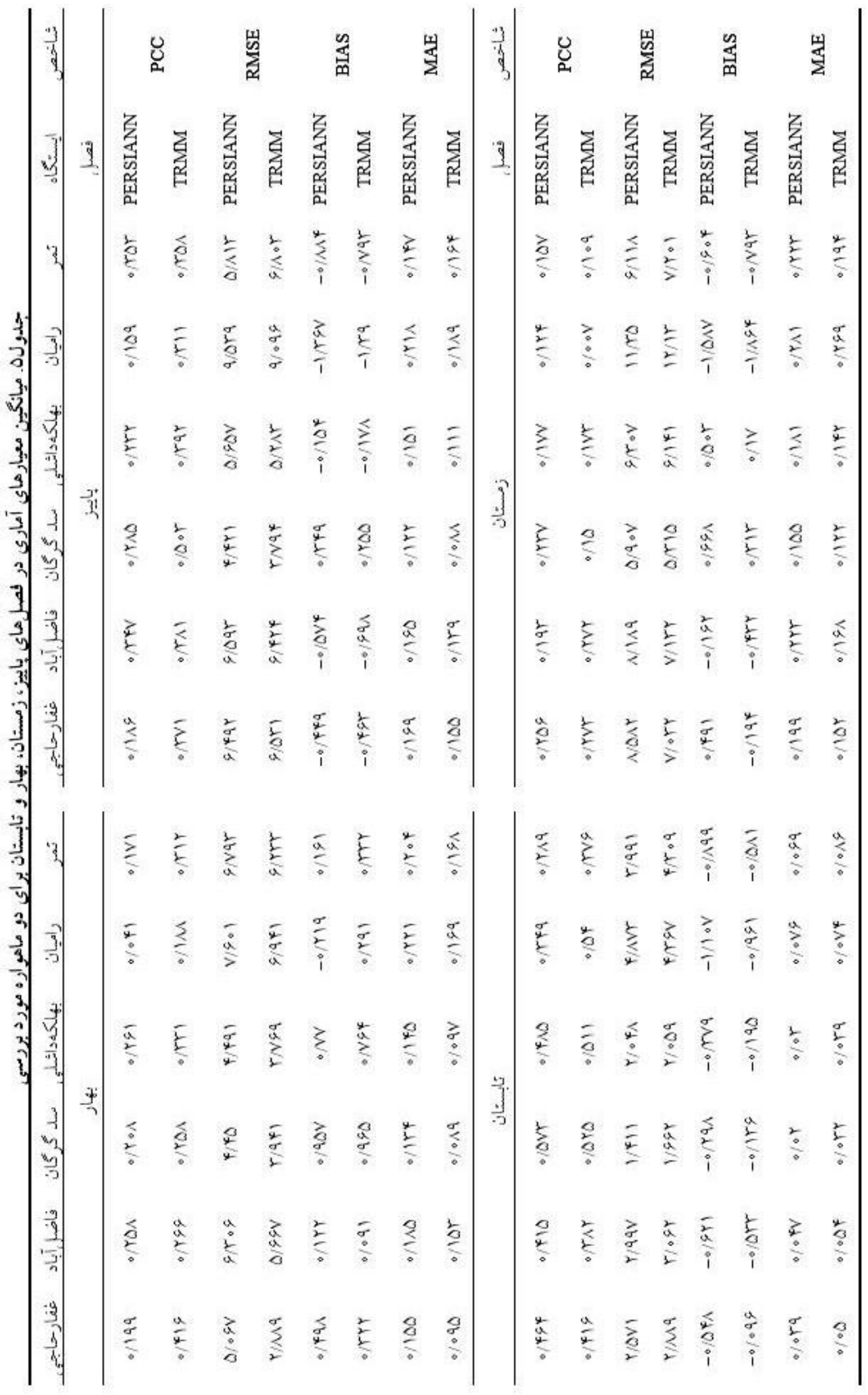




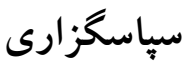

بدين وسيله از دانشخاه تهران به خاطر تأمين امكانات لازم جهت انجام اين تحقيق تشكر و قدردانى مىشود.
مشاهداتى در مقياس هاى زمانى ماهانـه و بيشـتر باشـــ. در ايسن مطالعه، نسخخه هفـتم TRMM-3B42 نسبـت بـه PERSIANN نتايج قابل قبول ترى را نشـان داد. لـذا، يِيشـنهاد مسىشـود ايسن بررسى با ماهوارههاى ديخر و در مناطق مختلف ايران نيز انجـام

\section{منابع مورد استفاده}

ا. حجازىزاده، ا.، ب. عليجانى، بֶ. ضياييان، م. كريمى و س. رفعتى. اهبا. ارزيابى بارش ماهوارهاى 3B43 و مقايسـه آن بـا مقـادير

$$
\text { حاصل از تكنيك درونيابى كريجينگ. سنجش از دور و GIS ايران \&(r): }
$$

r. شيروانى، ا. و ا. فخارى زاده شيرازى. سهوا. مقايسه مقادير مشاهداتى بارش و برآوردهاى ماهواره TRMM در استان فارس. نشـريه

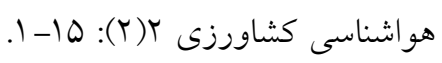

r. غضنفرى مقدم، م.، ا. عليز اده، م. موسوى بايكى، ع. فريد حسينى و م. بنايان اول. •وبا. مقايسه مــل PERSIANN بـا روشهـاى

درونيابى بهمنظور كاربرد در تخمين مقادير بارندگى روزانه (مطالعه موردى: خراسان شمالى). نشريه آب و خاك (علوم و صنايع

$$
\text { كشاورزى) }
$$

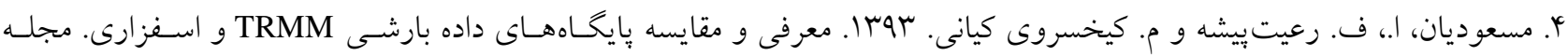

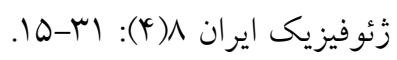

ه. ميان آبادى، آ.، ا. عليزاده، م. بنايان اول وع. فريدحسينى. بوها. ارزيابى آمارى خروجى مدل CMORPH در بـرآورد بـارش شـمال

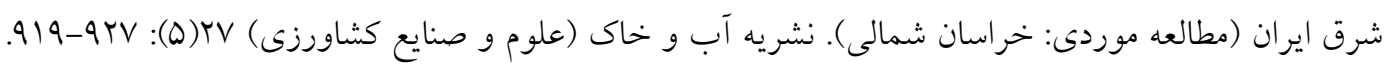

6. Ashouri, H., K. L. Hsu, S. Sorooshian, D. K. Braithwaite, K. R. Knapp, L. D. Cecil and O. P. Prat. 2015. PERSIANN-CDR: daily precipitation climate data record from multisatellite observations for hydrological and climate studies. Bull. Am. Meteor. Soc. 96(1): 69-83.

7. Chen, Y., E. E. Ebert, K. J. Walsh and N. E. Davidson. 2013. Evaluation of TRMM 3 B42 precipitation estimates of tropical cyclone rainfall using PACRAIN data. J. Geophys. Res. Atmospheres 118(5): 2184-2196.

8. Gao, Y. C. and M. F. Liu. 2013. Evaluation of high-resolution satellite precipitation products using rain gauge observations over the Tibetan Plateau. Hydrol. Earth Sys. Sci. 17(2): 837-849.

9. Ghajarnia, N., A. Liaghat and P. D. Arasteh. 2015. Comparison and evaluation of high resolution precipitation estimation products in Urmia Basin-Iran. Atmos. Res. 158: 50-65.

10. Gottschalck, J., J. Meng, M. Rodell and P. Houser. 2005. Analysis of multiple precipitation products and preliminary assessment of their impact on global land data assimilation system land surface states. J. Hydrometeor 6(5): 573-598.

11. Hong, Y., D. Gochis, J. T. Cheng, K. L. Hsu and S. Sorooshian. 2007. Evaluation of PERSIANN-CCS rainfall measurement using the NAME event rain gauge network. J. Hydrometeor 8(3): 469-482.

12. Huffman, G. J. and D. T. Bolvin. 2013. TRMM and other data precipitation data set documentation. PP. 1-40. In: NASA, Greenbelt, USA.

13. Hughes, D. A. 2006. Comparison of satellite rainfall data with observations from gauging station networks. J. Hydrol. 327(3): 399-410.

14. Javanmard, S., A. Yatagai, M. I. Nodzu, J. BodaghJamali and H. Kawamoto. 2010. Comparing high-resolution gridded precipitation data with satellite rainfall estimates of TRMM_3B42 over Iran. Adv. Geosci. 25: 119-125.

15. Kizza, M., I. Westerberg, A. Rodhe and H. K. Ntale. 2012. Estimating areal rainfall over lake Victoria and its basin using ground-based and satellite data. J. Hydrol. 464: 401-411.

16. Kottegoda, N.T. and R. Rosso. 2008. Applied Statistics for Civil and Environmental Engineers. Blackwell, Malden, MA. 
17. Liu, Z. 2015. Comparison of precipitation estimates between Version 7 3-hourly TRMM Multi-Satellite precipitation analysis (TMPA) near-real-time and research products. Atmos. Res. 153: 119-133.

18. Milewski, A., R. Elkadiri and M. Durham. 2015. Assessment and comparison of TMPA satellite precipitation products in varying climatic and topographic regimes in Morocco. Remote. Sens. 7(5): 5697-5717.

19. Moazami, S., S. Golian, Y. Hong, C. Sheng and M. R. Kavianpour. 2014. Comprehensive evaluation of four highresolution satellite precipitation products over diverse climate conditions in Iran. Hydrol. Sci. J. 61(2): 420-440.

20. Moazami, S., S. Golian, M. R. Kavianpour and Y. Hong. 2013. Comparison of PERSIANN and V7 TRMM Multisatellite precipitation analysis (TMPA) products with rain gauge data over Iran. Int. J. Remote Sens. 34(22): 81568171.

21. Qin, Y., Z. Chen, Y. Shen, S. Zhang and R. Shi. 2014. Evaluation of satellite rainfall estimates over the Chinese mainland. Remote. Sens. 6(11): 11649-11672.

22. Romilly, T. G. and M. Gebremichael. 2011. Evaluation of satellite rainfall estimates over Ethiopian river basins. Hydrol. Earth Sys. Sci. 15(5): 1505-1514.

23. Sorooshian, S., K. L. Hsu, X. Gao, H. V. Gupta, B. Imam and D. Braithwaite. 2000. Evaluation of PERSIANN system satellite-based estimates of tropical rainfall. Bull. Am. Meteor. Soc. 81(9): 2035-2046. 


\title{
Comparison of TRMM-3B42 V7 and PERSIANN Satellites Precipitation Data with Ground-Based Data (Case study: Gorganrood Basin, Iran)
}

\author{
D. Dezfooli, S. M. Hosseini-Moghari and K. Ebrahimi ${ }^{\star}$
}

(Received: Oct. 06-2015; Accepted: Feb. 08-2016)

\begin{abstract}
Precipitation is an important element of the hydrologic cycle and lack of this data is one of the most serious problems facing research on hydrological and climatic analysis. On the other hand, using satellite images has been proposed by many researchers as one of practical strategies to estimate precipitation. The present paper aims to evaluate the accuracy of satellite precipitation data, provided by PERSIANN and TRMM-3B42 V7 in Gorganrood basin, Iran. To achieve this aim, two sets of daily precipitation ground-based data, 2003 to 2004 and 2006 to 2007, from six stations of Gorganrood basin, named; "Tamer", "Ramian", "Bahalkeh-ye Dashli", "Gorgan Dam", "Ghaffar Haji” and "Fazel Abad" have been used in this paper. The evaluation indices have been calculated and analyzed in different time scales, including daily, monthly and seasonal. The results indicated that the two above mentioned satellite models are not accurate in daily scale. However, they showed reasonable accuracy in monthly and seasonal scales. The highest correlations between satellites and recorded data in daily and monthly scales, for TRMM-3B42 V7 in "Gorgan Dam" and "Bahlke Dashlei" stations, are 0.397 and 0.404 , respectively. The comparison of measured and satellite data of winter showed better agreement for PERSIANN model. However, TRMM-3B42 V7 shows better correlation in other seasons. The results also indicated that while TRMM-3B42 data displays higher correlation with measured data, PERSIANN provids better results in predicting the number of rainy days.
\end{abstract}

Keywords: Daily precipitation, Precipitation estimation, Remote sensing, Satellite images.

1. Dept. of Irrigation \& Reclamation Eng., Faculty of Agri. Eng. \& Technol., Univ. of Tehran, Tehran, Iran.

*: Corresponding Author, Email: EbrahimiK@ut.ac.ir 